\title{
CATCH UP GROWTH IN INFANTS BORN SMALL FOR GESTATIONAL AGE: BREASTFEEDING VS STANDARD FORMULA FEEDING IN TUNISIA
}

\author{
H. Bachrouche ${ }^{1}$, M.Y. Aissa ${ }^{1}$, K. Chraiet ${ }^{1}$, S. Rabah ${ }^{1}$, A. Guedria ${ }^{1}$, K. Aissa ${ }^{1}$ \\ ${ }^{1}$ EI Manar UNIVERSITY - University of medecine of Tunis - \\ Mohamed Tlatli Hospital of Nabeul, Pediatrics and Neonatology, Nabeul, Tunisia
}

Background:

Fetal growth restraint, if followed by a rapid catch up growth has been linked to an increased risk of diabetes and metabolic syndrome in adulthood. Long-term studies have shown that such risk is modulated by nutrition in early infancy.

Aim:

Our objective was to compare small for gestational age infants'(SGA)'s gains in weight, length and cranial circumference (cc) in a breastfeeding group (BFG) to those in a standard formula-feeding group (FFG).

Methods:

$>$ we conducted a prospective cohort study on 30 SGA infants with $\geq 37$ weeks of gestation recruited from a hospital in Tunisia during the year 2017.

$>$ When it was not possible to breastfeed, a standard formula was prescribed.

$>$ Then we measured weight, length and CC at 3 and 6 months of life

> Comparisons were done with Mann Whitney test with SPSS 20.0.

Results:

$>$ There were 17 infants in BFG and 13 in FFG.

$>$ There were no significant differences between them in the sex, gestational age and anthropometric parameters (Table 1).

$>$ There was a significant difference in the mean of weight at 6 months ( $p=0,04)$ (BFG: 7170 grams \pm 950 vs FFG: 7709 grams \pm 713 ). (chart 1)

$>$ However, there was no difference between the other means of the anthropometric parameters during the follow-up. (chart 2,3)

$>$ The gain of length between 3 and 6 months was also significant $(p=0,03)$ ( BFG $5,6 \mathrm{~cm} \pm 1,18$ vs FFG 7,2 cm $\pm 1,98$ ).
$>$ We have also found a significant difference in proteins levels $(p=0,029$ ) (BFG 59,5g/l $\pm 5,57$ vs $F F G 54,4 g / l \pm 2,87$ ) and in HDL cholesterol levels $(p=0,034) \quad(B F G \quad 0,57 \mathrm{mmol} / \pm 0,16$ vs $F F G$ $0,82 \mathrm{mmol} / \pm 0,29$ ) (Table 2).

Comments:

$>$ Our study confirms that breastfeeding provides a slower rate of weight gain than standard formula-feeding.

$>$ This finding suggests that protein-rich formula will be a provider of faster weight growth during the first months of life.

$>$ Breastfeeding is recommended as the optimal feeding method and nutrition for all infants but is particularly important for SGA.

$>$ Our biological results suggest that maternal milk promotes protein elevation and lowers HDL cholesterol levels in the 3 first months.

$>$ A weakness of our study is the relatively low number of participants because of their difficult recruitment.

Conclusion:

BFG have a slower catch up in growth at 6 months of life compared to FFG.

Exclusive breastfeeding until 6 months of life would be a recommendation that decrease the risk of adult diseases.

Table 1: Gestational age and anthropometric parameters at birth

\begin{tabular}{|c|c|c|c|c|}
\hline Mean & Gestational age & Birth Weight & Birth length & Birth cc \\
\hline BFG & 39,1 & 2510 & 46,7 & 32 \\
\hline FFG & 39,1 & 2426 & 47,8 & 32,9 \\
\hline
\end{tabular}

Table 2: Biologic results at 3 months

\begin{tabular}{|c|c|c|c|c|c|c|}
\hline & Hb & Pt & Creat & Glyc & HDL ch & TG \\
\hline BFG & $9,4 \mathrm{~g} / \mathrm{dl}$ & $59,5 \mathrm{~g}$ & $26,7 \mu \mathrm{mol}$ & $5,04 \mathrm{mmol}$ & $0,57 \mathrm{~g}$ & $1,4 \mathrm{~g}$ \\
\hline FFG & $9,9 \mathrm{~g} / \mathrm{dl}$ & $54,4 \mathrm{~g}$ & $28,5 \mu \mathrm{mol}$ & $5,1 \mathrm{mmol}$ & $0,82 \mathrm{~g}$ & 1,34 \\
\hline $\mathbf{p}$ & $\mathrm{NS}$ & $\mathbf{0 , 0 2 9}$ & $\mathrm{NS}$ & $\mathrm{NS}$ & $\mathbf{0 , 0 3 4}$ & $\mathrm{NS}$ \\
\hline
\end{tabular}

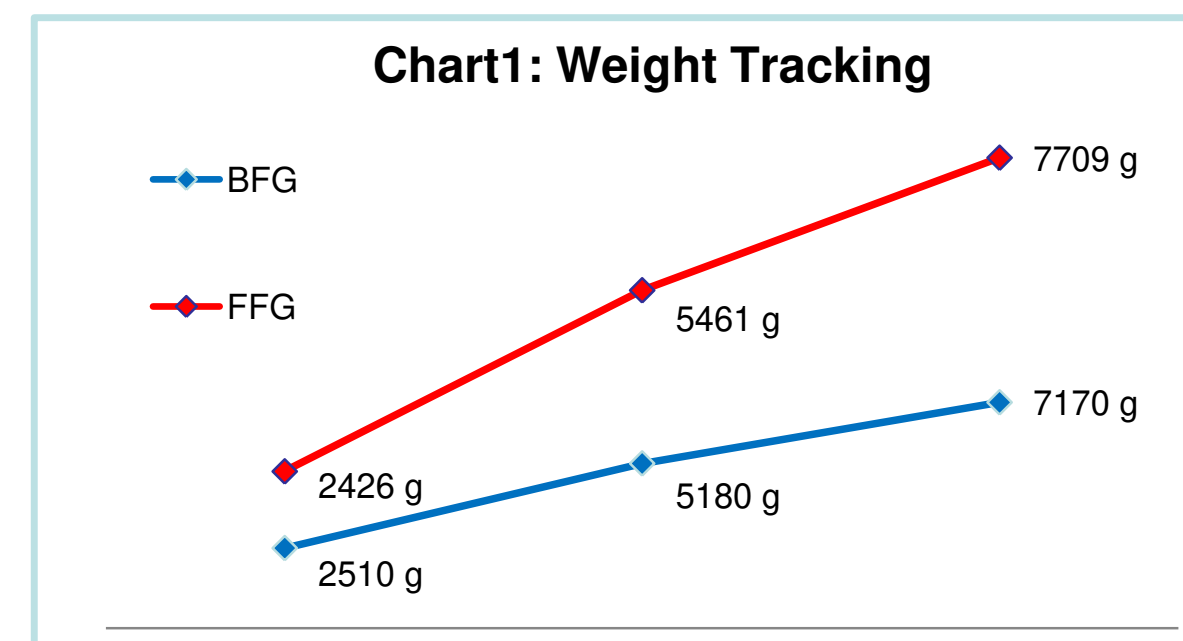

At Birth

3 months

6 months

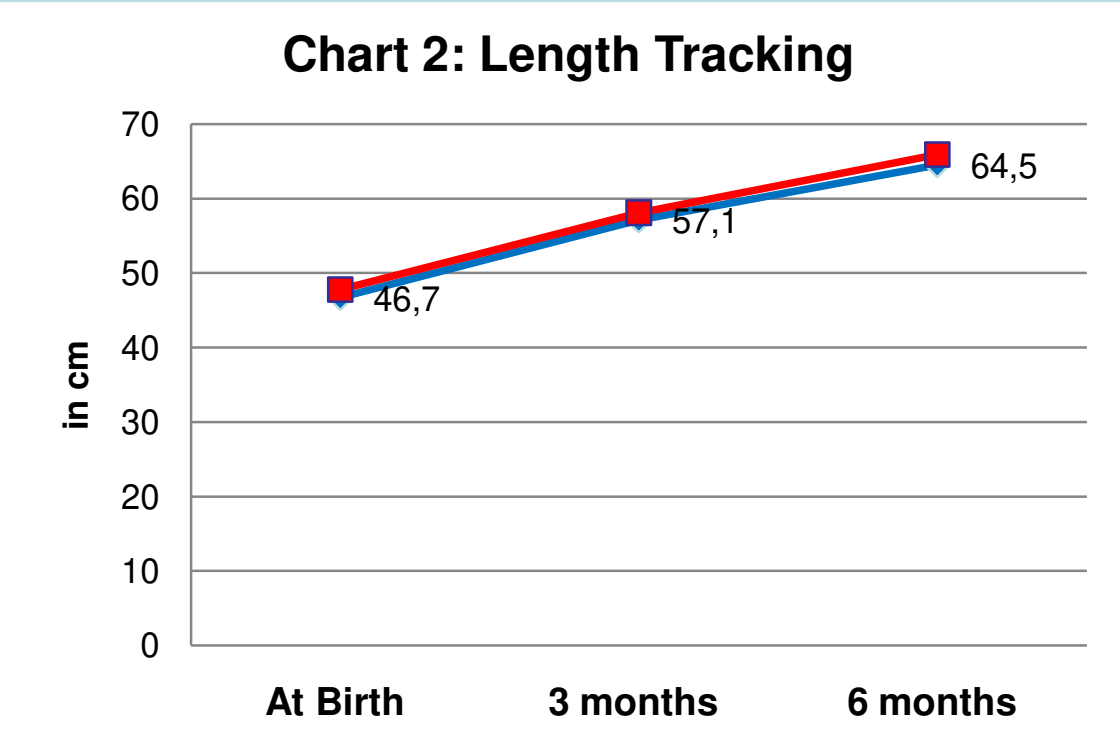

Chart 3:Cranial circumference Tracking

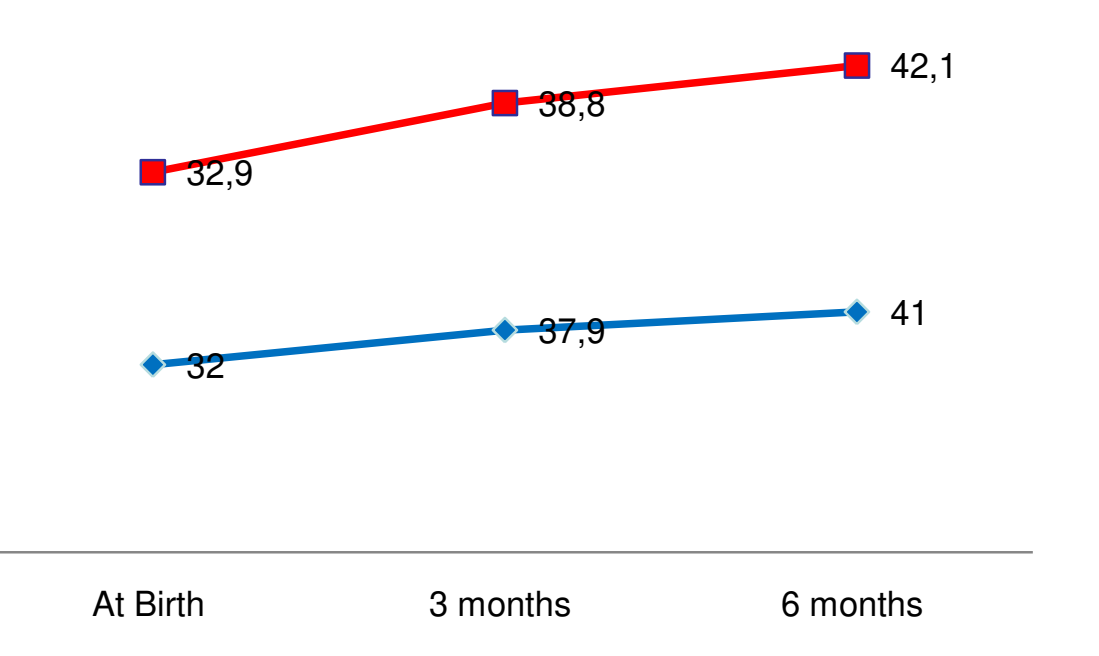

